\title{
Th1/Th2/Th17/Treg expression in cultured PBMCs with antiphospholipid antibodies
}

\author{
JING XIAO, FUFAN ZHU, XINLI LIU and JING XIONG \\ Department of Gynaecology and Obstetrics, The Second Xiangya Hospital, \\ Central South University, Changsha, Hunan 410011, P.R. China
}

Received May 3, 2012; Accepted August 16, 2012

DOI: $10.3892 / \mathrm{mmr} .2012 .1055$

\begin{abstract}
The aim of this study was to evaluate the expression of T-helper cell subtypes Th1, Th2, Th17 and Treg in antiphospholipid syndrome (APS), and whether they are related to anti-cardiolipin antibody (aPL) titers. Peripheral mononuclear cells (PBMCs) were isolated from healthy donors, and incubated with aPLs. Subsequent to a 48-h incubation, PBMCs were collected and detected by flow cytometry. The results revealed that aPLs at higher concentrations may induce a significant increase in Th2 and Th17 frequencies, as opposed to a significant decrease in Th1 and Treg frequencies and the Th1/Th2 ratio. These results indicate that there is a Th1/Th2 imbalance, a Th17 upregulation and a Treg downregulation present in APS, and that these factors are positively correlated with aPL titers, suggesting a potential role of Th cells in the pathogenesis of APS.
\end{abstract}

\section{Introduction}

Antiphospholipid syndrome (APS) is characterized clinically by recurrent fetal loss and/or thrombosis, and serologically by the persistent presence of antiphospholipid antibodies (aPLs). The aPLs mainly include anti-cardiolipin antibodies (aCLs), lupus anticoagulant (LA) and anti- $\beta 2$ GPI antibodies (anti- $\beta 2 \mathrm{GPI}$ ). The poor obstetric outcomes in pregnant women with APS are also characterized by the occurrence of growth retardation and pre-eclampsia (1).

For decades, it has been widely adopted by researchers that higher titers of aPLs induce clinical manifestations in APS (2-5), although the approaches varied regarding the division of low/high titers. The latest revised approaches suggest that due to medium or high titers of IgG or IgM-class aCL antibodies,

Correspondence to: Professor Fufan Zhu, Department of Gynaecology and Obstetrics, The Second Xiangya Hospital, Central South University, 139 Renmin Middle Rd, Changsha, Hunan 410011, P.R. China

E-mail: fufanzhu@163.com

Key words: antiphospholipid antibodies, T-helper cell subtypes Th1/Th2/Th17, regulatory $\mathrm{T}$ cell, titers medium and/or high titers of IgG or IgM-class anti- $\beta 2 \mathrm{GPI}$ antibodies and positivity for LA, testing for APS should be performed twice, at least 12 weeks apart (1).

Accumulating evidence demonstrates that APS is an autoantibody-mediated systemic autoimmune disease (6-7). $\mathrm{CD}^{+} \mathrm{T}$ helper cells (Th cells) play central roles in immunoregulation and immuno-stimulation. Th cells are divided into 4 subtypes: IFN- $\gamma$-secreting Th1, IL-4-secreting Th2, IL-17-producing Th17 cells and $\mathrm{CD}^{+} \mathrm{CD} 25^{+} \mathrm{Foxp} 3^{+}$regulatory $\mathrm{T}$ cells (Tregs). Although there are various studies available on the role of Th1 and Th2 cells in autoimmune diseases, their mechanisms in APS have not been fully elucidated yet. Moreover, the published data concerning the Th1/Th2 type of cellular immune response in APS have been inaccurate both in human and mouse models. Certain studies report a Th2-predominant state (8-10), however, there are studies reporting a shift to a Th1 response (11-13). The roles and mechanisms of Treg in APS are both unclear. We found a sole study in a mouse model of APS reporting the downregulation of the number and function of $\mathrm{CD} 4^{+} \mathrm{CD} 25^{+} \mathrm{Foxp} 3^{+}$Treg cells (14). Although Th17 cells have been thoroughly studied in autoimmune diseases, they have never been reported in APS. Thus, the present study aimed to closely examine Th differentiation and to identify the Th1/Th2 paradigm in APS, to delineate the way Th17 and Treg subtypes change in APS, to determine their roles and to examine whether they are correlated with the aPL titers.

\section{Materials and methods}

Patients and aPL antibody preparation. Serum samples were obtained from 4 outpatients of the Obstetrics and Gynecology Department of the Second Xiangya Hospital, Hunan, China. The study was approved by the local Research Ethics Committee and all patients provided informed consent. The outpatients were diagnosed with APS characterized by at least two fetal losses and positive aPL antibodies (aCL- and/or anti$\beta 2$ GPI-positive and LA-negative). The diagnoses were made on two occasions, at least 12 weeks apart. Serum samples from patients were collected after the clinical event, without immunosuppressive therapy. The serum samples were boiled $\left(30 \mathrm{~min}\right.$ at $56^{\circ} \mathrm{C}$ ) and $\mathrm{IgG}$ was purified by ammonium sulfate precipitation. The titers of aCL-IgG and anti- $\beta 2$ GPI-IgG were measured with an enzyme-linked immunosorbent assay 
Table I. Frequencies of Th1/Th2/Th17/ Treg expression in different groups detected by flow cytometry (mean \pm SD).

\begin{tabular}{lccccc}
\hline $\begin{array}{l}\text { Group } \\
(\mathrm{n}=5)\end{array}$ & $\begin{array}{c}\text { Th1 } \\
(\%)\end{array}$ & $\begin{array}{c}\text { Th2 } \\
(\%)\end{array}$ & $\begin{array}{c}\text { Th1/Th2 ratio } \\
(\%)\end{array}$ & $\begin{array}{c}\text { Th17 } \\
(\%)\end{array}$ & $\begin{array}{c}\text { Treg } \\
(\%)\end{array}$ \\
\hline Control & $5.51 \pm 0.62$ & $4.72 \pm 0.26$ & $1.24 \pm 0.12$ & $3.81 \pm 0.54$ & $1.77 \pm 0.65$ \\
Negative & $5.63 \pm 0.75$ & $4.77 \pm 0.36$ & $1.18 \pm 0.15$ & $3.97 \pm 0.66$ & $1.63 \pm 0.42$ \\
$5 \%$ aPLs & $6.16 \pm 1.25$ & $4.68 \pm 0.54$ & $1.32 \pm 0.29$ & $4.23 \pm 1.15$ & $1.34 \pm 0.52$ \\
$10 \%$ aPLs & $.4 .43 \pm 1.43^{\mathrm{b}}$ & $4.66 \pm 0.67$ & $0.97 \pm 0.35$ & $4.23 \pm 0.66$ & $1.21 \pm 0.31$ \\
$15 \%$ aPLs & $.3 .59 \pm 1.03^{\mathrm{a}, \mathrm{b}}$ & $5.16 \pm 0.71$ & $.0 .70 \pm 0.18^{\mathrm{a}}$ & $4.76 \pm 0.39$ & $0.92 \pm 0.32^{\mathrm{a}}$ \\
$25 \%$ aPLs & $. .2 .68 \pm 0.77^{\mathrm{a}, \mathrm{b}, \mathrm{c}}$ & $. .5 .58 \pm 0.34^{\mathrm{a}, \mathrm{b}, \mathrm{c}}$ & $. .0 .49 \pm 0.16^{\mathrm{a}, \mathrm{b}}$ & $.5 .38 \pm 0.39^{\mathrm{a}}$ & $0.49 \pm 0.27^{\mathrm{a}, \mathrm{b}, \mathrm{c}}$ \\
\hline
\end{tabular}

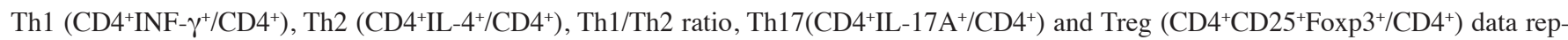

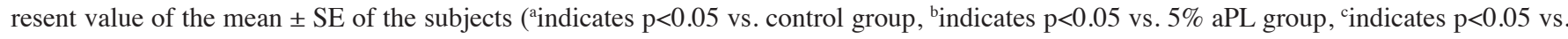
$10 \%$ aPL group).

(ELISA) kit (Euroimmun, Lübeck, Germany), and were found to be 56 and $170 \mathrm{U} / \mathrm{ml}$, respectively. Control human serum samples from 4 healthy non-autoimmune individuals were obtained in the same way. Purified samples were stored at $-80^{\circ} \mathrm{C}$ for later use.

Peripheral mononuclear cell (PBMC) isolation and sample preparation. Heparinized venous blood was obtained from healthy adult volunteers negative for aPLs. PBMCs were isolated by centrifugation $(900 \mathrm{x} \mathrm{g}$ for $30 \mathrm{~min}$, at room temperature) with Ficoll-Hypaque (EZ-Sep ${ }^{\mathrm{TM}}$ Human Lymphocyte Separation Medium). Cells were then collected, washed 3 times with PBS and suspended in RPMI-1640 (Gibco, Carlsbad, CA, USA), supplemented with $100 \mathrm{M} / \mathrm{ml}$ penicillin (Gibco), $100 \mu \mathrm{g} / \mathrm{ml}$ streptomycin (Gibco) and 10\% fetal calf serum.

PBMCs at the concentration of $1 \times 10^{7}$ cells $/ \mathrm{ml}$ were added onto 12-well microtiter plates, and incubated with 5\% PBS (control group), 5\% normal human IgG (negative group) or different titers of aPLs $(5,10,15$ or $25 \%)$, for $48 \mathrm{~h}$ at $37^{\circ} \mathrm{C}$ with $5 \% \mathrm{CO}_{2}$.

Flow cytometry. Flow cytometric analysis of the Th cell subtypes was performed using FITC anti-human CD4 (clone OKT4; Biolegend, San Diego, CA, USA), PE anti-human IFN-r (clone 4S.B3; Biolegend), APC anti-human IL-4 (clone 8D4-8; Biolegend), PE/Cy7 anti-human IL-17A (clone BL168; Biolegend), PE anti-human CD25 (clone BC96; Biolegend) and APC anti-human Poxp3 (clone 236A/E7; eBioscience, San Diego, CA, USA).

For intracellular cytokine staining, PBMCs at the concentration of $2 \times 10^{6}$ cells $/ \mathrm{ml}$ were stimulated with phorbol myristate acetate (PMA; $20 \mathrm{ng} / \mathrm{ml}$; Sigma, St. Louis, MO, USA) and ionomycin (1,000 ng/ml; Sigma) for $1 \mathrm{~h}$, then incubated with GolgiPlug ( $1 \mu \mathrm{l} / \mathrm{ml}$; BD, USA) for $4 \mathrm{~h}$. Then the stimulated cells were collected and washed twice with PBS, and then stained with FITC anti-human CD4 for 30 min on ice in the dark. The cells were then washed twice with PBS, and fixed in fixation buffer (Biolegend) for $30 \mathrm{~min}$ at room temperature in the dark. Subsequent to this, cells were washed twice with permeabilizing solution buffer (Biolegend) for
6 min at room temperature. They were then stained with PE anti-human IFN- $\gamma$, APC anti-human IL-4, PE/Cy7 anti-human IL-17A for $30 \mathrm{~min}$ on ice in the dark. After washing, the cells were fixed in $1 \%$ paraformaldehyde and stored at $4^{\circ} \mathrm{C}$ in the dark for subsequent detection.

For Treg staining, PBMCs at the concentration of $2 \times 10^{6}$ cells $/ \mathrm{ml}$ were collected and washed twice with PBS, and stained for $30 \mathrm{~min}$ on ice in the dark with FITC anti-human CD4 and PE anti-human CD25. The cells were then washed twice with PBS and fixed in fixation buffer (Biolegend) for $30 \mathrm{~min}$ at room temperature in the dark. Subsequent to this, cells were washed twice with permeabilizing solution buffer (Biolegend) for $6 \mathrm{~min}$ at room temperature. They were then stained with APC anti-human Poxp3 for $30 \mathrm{~min}$ on ice in the dark. After washing, the cells were fixed in $1 \%$ paraformaldehyde and stored at $4^{\circ} \mathrm{C}$ in the dark for subsequent detection.

The cells were analyzed by Beckman Coulter FC500 (Beckman, Miami, FL, USA). A total of 10,000 cells were counted in each sample. A gate was set on the lymphocytes using characteristic forward scatter (FSC) and side scatter (SSC) parameters. Isotype-matched FITC mouse IgG1 antibody, PE mouse IgG1 antibody, APC mouse IgG1 antibody and $\mathrm{PE} / \mathrm{Cy} 7$ mouse IgG1 antibody (Biolegend) were used as controls.

Statistical analysis. Each experiment was repeated 3 times with similar results. Statistical analysis was performed using SPSS 17.0. Statistically significant differences in the 6 experimental groups were analyzed by one-way ANOVA. Differences between 2 groups were analyzed for homogeneity of variance, by the least significant difference (LSD) or by Dunnet T3. Correlations in the 2 indices were analyzed by the Pearson test. $\mathrm{P}<0.05$ was considered to indicate a statistically significant difference.

\section{Results}

$a P L$ titers and groups. The aPLs were detected and recorded as follows: aCL IgGs were $56 \mathrm{U} / \mathrm{ml}$, anti- $\beta 2 \mathrm{GPI}$ IgGs were $170 \mathrm{U} / \mathrm{ml}$. In accordance with the literature, we produced concentrations of 5, 10, 15 and $25 \%$ aPLs and these formed 

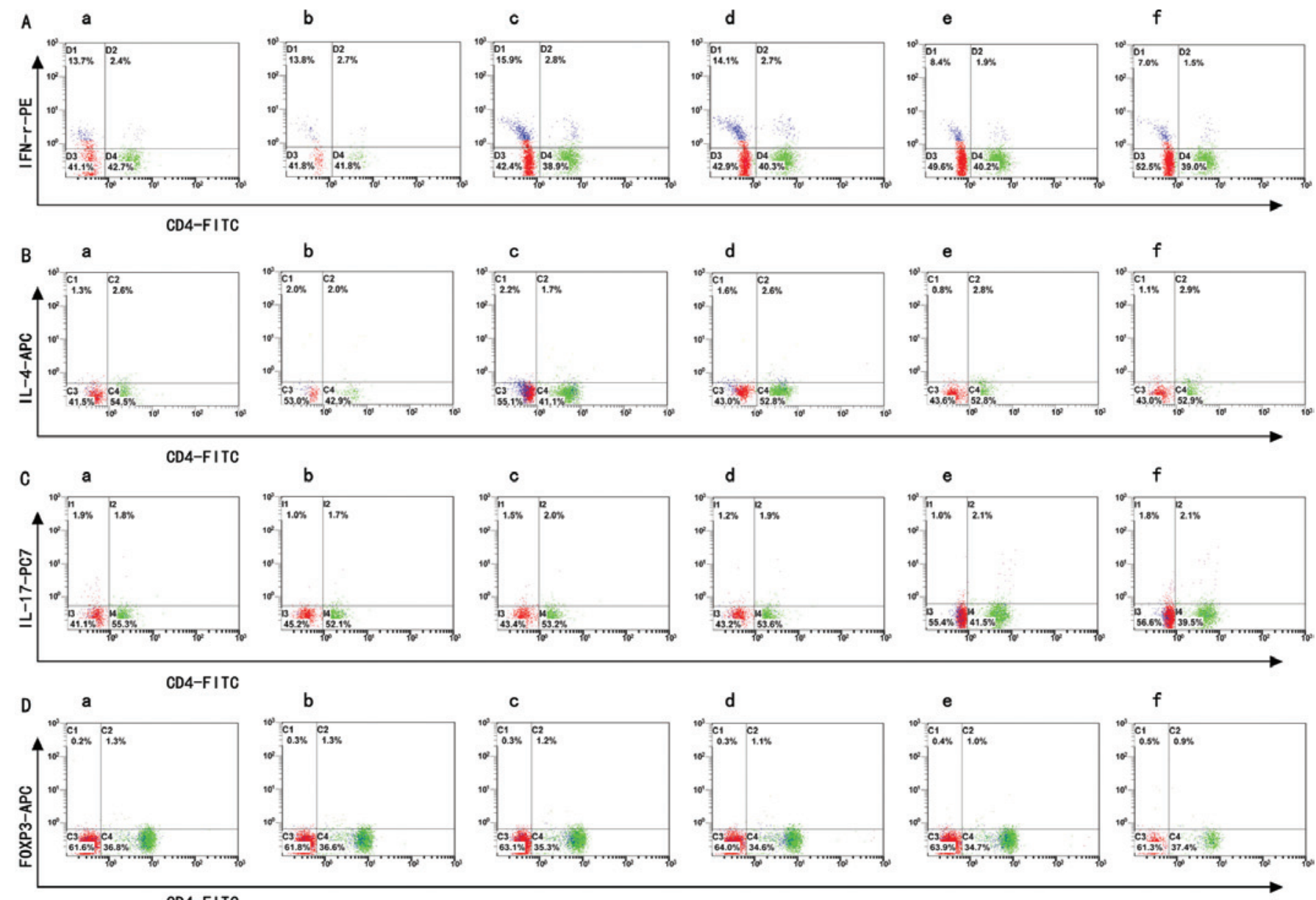

Figure 1. FACS data of Th subtypes in different groups. (a-f) Normal, negative, 5\%, 10\%, 15\% and 25\% aPL groups, respectively. (A) Th1 expression; (B) Th2 expression; (C) Th17 expression; (D) Treg expression.
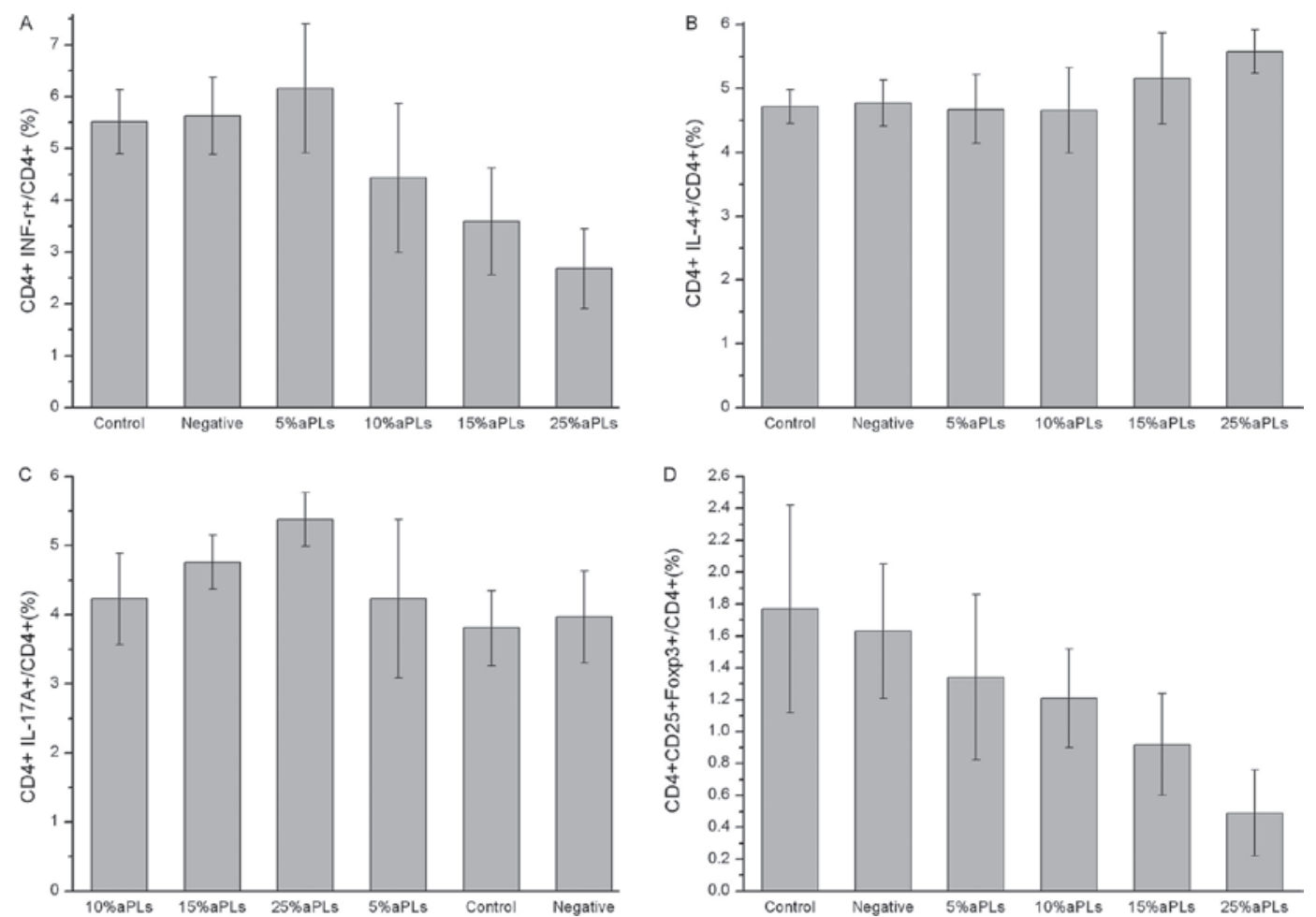

Figure 2. Th subtype changes with aPL titers. Frequencies of (A) Th1, (B) Th2, (C) Th17 and (D) Treg cells in different groups. 
Table II. Correlation between Th subtypes and aPL titers.

\begin{tabular}{|c|c|c|}
\hline & $\mathrm{R}$ & P-value \\
\hline $\mathrm{CD} 4^{+} \mathrm{INF}^{-} \gamma^{+} / \mathrm{CD} 4^{+}(\mathrm{Th} 1)$ & -0.702 & 0.000 \\
\hline $\mathrm{CD}^{+}{ }^{+} \mathrm{IL}_{-} 4^{+} / \mathrm{CD} 4^{+}(\mathrm{Th} 2)$ & 0.468 & 0.009 \\
\hline Th1/Th2 ratio & -0.752 & 0.000 \\
\hline $\begin{array}{l}\mathrm{CD}^{+}{ }^{+} \mathrm{IL}_{-}-17 \mathrm{~A}^{+} / \\
\mathrm{CD}^{+}(\mathrm{Th} 17)\end{array}$ & 0.617 & 0.000 \\
\hline $\begin{array}{l}\mathrm{CD}^{+}{ }^{+} \mathrm{CD} 25^{+} \mathrm{Foxp}^{+} / \\
\mathrm{CD}^{+}{ }^{+} \text {(Treg) }\end{array}$ & -0.727 & 0.000 \\
\hline
\end{tabular}

the aPL groups. There were 2.8, 5.6, 8.4 and $14 \mathrm{U} / \mathrm{ml}$ aCL IgG and 8.5, 17, 25.5 and $42.5 \mathrm{U} / \mathrm{ml}$ anti- $\beta 2 \mathrm{GPI} \mathrm{IgG}$ in the groups, respectively. The group with $5 \%$ aPLs was the negative concentration group (aPL titers $<10 \mathrm{U} / \mathrm{ml}$ ), the $10 \%$ group had aPL titers $<20 \mathrm{U} / \mathrm{ml}$, the $15 \%$ group had aPL titers $>20 \mathrm{U} / \mathrm{ml}$ but $<40 \mathrm{U} / \mathrm{ml}$, whereas the $25 \%$ group with a medium/high concentration, had aPL titers $>40 \mathrm{U} / \mathrm{ml}$.

Th1/Th2/Th17/Treg subtype changes detected by flow cytometry. The data in Table I demonstrate that the Th1, Th2, Th17 and Treg cell expression and the Th1/Th2 ratio changed in PBMCs cultured with different titers of aPLs. We found that the subtypes of the Th cells were changed significantly in the $15 \%$ aPL group and even moreso in the $25 \%$ aPL group, compared to the normal group. In the 5\% and $10 \%$ aPL groups Th expression showed no difference. The flow cytometry images are shown in Fig. 1, while the bar graphs of Th1, Th2, Th17 and Treg cell expression are shown in Fig. 2.

Th subtype changes with aPL titers. As shown in Table II, changes of Th cells were found to be dose-dependent with aPLs titers. Th1 expression, Th1/Th2 ratio and Treg expression were decreased along with a higher aPL concentration, although the Th2 and Th17 expression was increased.

\section{Discussion}

Th1/Th2 imbalance in APS. In this study we found that the Th1 frequencies were lower after a 48-h culturing with aPLs, while the Th2 frequencies showed a rising tendency, and the Th1/Th2 ratio was expressly decreased. In conclusion, aPL antibodies at higher concentrations induce significant Th2 dominance.

Certain studies demonstrate that a shift from Th1- to Th2-driven humoral immunity had been found in normal pregnancies and considered to be beneficial for an immunologically successful continuation of the pregnancy $(15,16)$. Regarding the Th1/Th2 imbalance in patients with recurrent abortion, most scientists reported an increased Th1 expression $(17,18)$, while immunotherapy may induce the dominance of Th2 cells (18), which may reduce the abortion rate. The participants with recurrent abortion discussed in the aforementioned articles, however, had no positive aPL antibodies, thus it remains uncertain whether the Th1/Th2 paradigm shift in recurrent abortion is caused by aPLs. We only found a few relevant studies and their conclusions were contradictory (8-13), possibly resulting from differences in the experimental approaches. Th1 and Th2 responses have both been reported to play a prominent role in the pathogenesis of aPL-associated tissue injuries. For a normal pregnancy, the aPL level must be maintained within an appropriate range, as an overshift to either side may induce a miscarriage.

Treg downregulation in APS model. Recently, $\mathrm{CD} 4{ }^{+} \mathrm{CD} 25^{+} \mathrm{Foxp}^{+}$Treg cells were recognized to play a crucial role in the maintenance of normal immune tolerance. The functions of effector T cells, such as Th1, Th2 and Th17 were regulated by Treg cells. In certain autoimmune diseases, such as systemic lupus erythematosus (SLE), rheumatoid arthritis (RA), primary Sjogren's syndrome (pSs) and multiple sclerosis (MS), Treg cells have been reported to decrease in number (19-23). Decreased Treg cells also contributed to recurrent abortion in the absence of antiphospholipid syndrome (24-26).

In the present study, we demonstrated that the frequencies of Treg cells were significantly lower subsequent to aPL culturing, both in the $15 \%$ and the $25 \%$ aPL group, compared to the control group. The aPLs induced significant Treg downregulation even at lower concentrations, which was partly consistent with the study conducted by Fu et al on APS in a mouse model (14). Treg downregulation may be another reason for recurrent abortion in APS.

Th17 upregulation. Th17, a novel subtype of T helper cells, actively participates in inflammation and autoimmunity and is distinct from the well-described Th1 and Th2 cells (27-28). Th17 cells have been reported to accumulate in individuals with recurrent abortions without APS (29-31); their role in APS, however, has never been reported. In the present study, we have initially found that the frequencies of Th17 cells were higher subsequent to aPL-culturing, and were also dosedependent.

In addition, a Th17/Treg imbalance was observed in our study, which may be another cause of APS, as naïve CD4 ${ }^{+}$ $\mathrm{T}$ cells (nTh) differentiate into Treg cells under the influence of TGF- $\beta$. However, when exposed to TGF- $\beta$ and IL-6, nTh cells develop into Th17 cells (32). The Th17/Treg cells have a complex relationship, and Th17 cells may affect Treg cell-induced transplant tolerance.

The possible pathogenic titers of aPLs. The latest revised approach to diagnosis is that APS should be detected twice, at least 12 weeks apart, due to medium and high titers antibodies. After decades of clinical research on APS, scholars have found that aPL > 40 GPL or MPL unit $(1 \mu \mathrm{g} / \mathrm{ml}$ affinity purification of IgG or IgM anti-cardiolipin antibody) may lead to clinical manifestations, while others found aPL even >20 GPL or MPL unit may affect prognosis. In in vitro studies Ferrara et al found that aPL antibodies upregulate tissue factor expression in epithelial cells in a dose-dependent manner, which is associated with thrombogenic effects (33), while Mulla et al found a decreased viability in trophoblast cells in response to the elevated anti- $\beta 2$ GPI antibody titers (34). Since aPL concentrations are associated with the disease, it is necessary to determine the appropriate concentration that would provide sufficient but not excessive treatment.

In the present study, we distinguished 4 groups with different aPL concentrations (5, 10, 15 and 25\% groups) and 
found the expression of the four Th subsets and Th1/Th2 ratios have dose-dependent changes. At higher concentrations the differences in the Th subtypes were statistically significant. In the 25\% aPL group, all 4 Th subtypes and the Th1/Th2 ratio showed significant changes. In the $15 \%$ aPL group, only the Th1 and Treg expression and Th1/Th2 ratio showed significant changes. In other words, the Th subtypes changed even if the concentration was less than 40 GPL units. The results of the present study revealed that clinical treatment was required not only for patients with an aPL titer $>40$ GPL or MPL unit, but also for patients with lower titers. In order to determine the specific aPL concentration required for treatment, further research is needed.

In conclusion, the data presented in this study demonstrated that the aPL titers play a crucial role in the pathogenesis of APS. These results also demonstrated that there is a Th1/Th2 imbalance, a Th17 upregulation and a Treg downregulation in APS, and that these factors are positively correlated with the antibody titers, suggesting a potential role of Th cells in the pathogenesis of APS. The Th cell changes provide a novel method for the treatment of patients with APS.

\section{References}

1. Miyakis S, Lockshin MD, Atsumi $\mathrm{T}$, et al: International consensus statement on an update of the classification criteria for definite antiphospholipid syndrome (APS). J Thromb Haemost 4: 295-306, 2006

2. Silver RM, Porter TF, van Leeuween I, Jeng G, Scott JR and Branch DW: Anticardiolipin antibodies: clinical consequences of 'low titers'. Obstet Gynecol 87: 494-500, 1996.

3. Levine SR, Salowich-Palm L, Sawaya KL, et al: IgG anticardiolipin antibody titer $>40$ GPL and the risk of subsequent thrombo-occlusive events and death. A prospective cohort study. Stroke 28: 1660-1665, 1997.

4. Erkan D, Barbhaiya M, George D, Sammaritano L and Lockshin M: Moderate versus high-titer persistently anticardiolipin antibody positive patients: are they clinically different and does high-titer anti-beta 2-glycoprotein-I antibody positivity offer additional predictive information? Lupus 19: 613-619, 2010.

5. Tuhrim S, Rand JH, Wu XX, et al: Elevated anticardiolipin antibody titer is a stroke risk factor in a multiethnic population independent of isotype or degree of positivity. Stroke 30: $1561-1565,1999$.

6. Bakimer R, Fishman P, Blank M, Sredni B, Djaldetti M and Shoenfeld Y: Induction of primary antiphospholipid syndrome in mice by immunization with a human monoclonal anticardiolipin antibody (H-3). J Clin Invest 89: 1558-1563, 1992.

7. Pierangeli SS and Harris EN: Induction of phospholipid-binding antibodies in mice and rabbits by immunization with human beta 2 glycoprotein 1 or anticardiolipin antibodies alone. Clin Exp Immunol 93: 269-272, 1993.

8. Krause I, Blank M, Levi Y, Koike T, Barak V and Shoenfeld Y: Anti-idiotype immunomodulation of experimental anti-phospholipid syndrome via effect on Th1/Th2 expression. Clin Exp Immunol 117: 190-197, 1999.

9. Fischer K, Collins H, Taniguchi M, Kaufmann SH and Schaible UE: IL-4 and T cells are required for the generation of IgG1 isotype antibodies against cardiolipin. J Immunol 168: 2689-2694, 2002.

10. Soltesz P, Der H, Veres K, et al: Immunological features of primary anti-phospholipid syndrome in connection with endothelial dysfunction. Rheumatology (Oxford) 47: 1628-1634, 2008.

11. Karakantza M, Theodorou GL, Meimaris N, et al: Type 1 and type 2 cytokine-producing CD4+ and CD8+ T cells in primary antiphospholipid syndrome. Ann Hematol 83: 704-711, 2004.

12. Amital H, Gilburd B and Shoenfeld Y: Probiotic supplementation with Lactobacillus casei (Actimel) induces a Th1 response in an animal model of antiphospholipid syndrome. Ann N Y Acad Sci 1110: 661-669, 2007.
13. Visvanathan S and McNeil HP: Cellular immunity to beta 2-glycoprotein-1 in patients with the antiphospholipid syndrome. J Immunol 162: 6919-6925, 1999.

14. Fu J, Fy Q and Si CP: Changes of CD4+CD25+ regulatory T cells and foxp 3 expression in rats with experimental anti-phospholipid antibody syndrome. Matern Child Healthcare Chin 25: 821-824, 2010.

15. Lin H, Mosmann TR, Guilbert L, Tuntipopipat S and Wegmann TG: Synthesis of T helper 2-type cytokines at the maternal-fetal interface. J Immunol 151: 4562-4573, 1993.

16. Marzi M, Vigano A, Trabattoni D, et al: Characterization of type 1 and type 2 cytokine production profile in physiologic and pathologic human pregnancy. Clin Exp Immunol 106: 127-133, 1996.

17. Sugiura-Ogasawara M, Furukawa TA, Nakano Y, Hori S, Aoki K and Kitamura T: Depression as a potential causal factor in subsequent miscarriage in recurrent spontaneous aborters. Hum Reprod 17: 2580-2584, 2002

18. Yokoo T, Takakuwa K, Ooki I, Kikuchi A, Tamura M and Tanaka K: Alteration of TH1 and TH2 cells by intracellular cytokine detection in patients with unexplained recurrent abortion before and after immunotherapy with the husband's mononuclear cells. Fertil Steril 85: 1452-1458, 2006.

19. Bonelli M, Savitskaya A, von Dalwigk K, et al: Quantitative and qualitative deficiencies of regulatory $\mathrm{T}$ cells in patients with systemic lupus erythematosus (SLE). Int Immunol 20: 861-868, 2008.

20. Behrens F, Himsel A, Rehart S, et al: Imbalance in distribution of functional autologous regulatory $\mathrm{T}$ cells in rheumatoid arthritis. Ann Rheum Dis 66: 1151-1156, 2007.

21. Li X, Qian L, Wang G, et al: T regulatory cells are markedly diminished in diseased salivary glands of patients with primary Sjogren's syndrome. J Rheumatol 34: 2438-2445, 2007.

22. Dalla Libera D, Di Mitri D, Bergami A, et al: T regulatory cells are markers of disease activity in multiple sclerosis patients. PLoS One 6: e21386, 2011.

23. Miyara M, Gorochov G, Ehrenstein M, Musset L, Sakaguchi S and Amoura Z: Human FoxP3+ regulatory T cells in systemic autoimmune diseases. Autoimmun Rev 10: 744-755, 2011.

24. Sasaki Y, Sakai M, Miyazaki S, Higuma S, Shiozaki A and Saito S: Decidual and peripheral blood CD4+CD25+ regulatory $\mathrm{T}$ cells in early pregnancy subjects and spontaneous abortion cases. Mol Hum Reprod 10: 347-353, 2004.

25. Fraccaroli L, Alfieri J, Larocca L, et al: A potential tolerogenic immune mechanism in a trophoblast cell line through the activation of chemokine-induced $\mathrm{T}$ cell death and regulatory $\mathrm{T}$ cell modulation. Hum Reprod 24: 166-175, 2009.

26. Arruvito L, Sotelo AI, Billordo A and Fainboim L: A physiological role for inducible FOXP3(+) Treg cells. Lessons from women with reproductive failure. Clin Immunol 136: 432-441, 2010.

27. McKenzie BS, Kastelein RA and Cua DJ: Understanding the IL-23-IL-17 immune pathway. Trends Immunol 27: 17-23, 2006.

28. Steinman L: A brief history of $\mathrm{T}(\mathrm{H}) 17$, the first major revision in the $\mathrm{T}(\mathrm{H}) 1 / \mathrm{T}(\mathrm{H}) 2$ hypothesis of $\mathrm{T}$ cell-mediated tissue damage. Nat Med 13: 139-145, 2007.

29. Wang WJ, Hao CF, Qu QL, Wang X, Qiu LH and Lin QD: The deregulation of regulatory $\mathrm{T}$ cells on interleukin-17-producing $\mathrm{T}$ helper cells in patients with unexplained early recurrent miscarriage. Hum Reprod 25: 2591-2596, 2010.

30. Liu YS, Wu L, Tong XH, et al: Study on the relationship between Th17 cells and unexplained recurrent spontaneous abortion. Am J Reprod Immunol 65: 503-511, 2011.

31. Nakashima A, Ito M, Shima T, Bac ND, Hidaka T and Saito S: Accumulation of IL-17-positive cells in decidua of inevitable abortion cases. Am J Reprod Immunol 64: 4-11, 2010.

32. Ogura H, Murakami M, Okuyama Y, et al: Interleukin-17 promotes autoimmunity by triggering a positive-feedback loop via interleukin-6 induction. Immunity 29: 628-636, 2008.

33. Ferrara DE, Swerlick R, Casper K, et al: Fluvastatin inhibits up-regulation of tissue factor expression by antiphospholipid antibodies on endothelial cells. J Thromb Haemost 2: 1558-1563, 2004.

34. Mulla MJ, Brosens JJ, Chamley LW, et al: Antiphospholipid antibodies induce a pro-inflammatory response in first trimester trophoblast via the TLR4/MyD88 pathway. Am J Reprod Immunol 62: 96-111, 2009. 